Tropical Journal of Pharmaceutical Research March 2020; 19 (3): 623-628

ISSN: $1596-5996$ (print); 1596-9827 (electronic)

(C) Pharmacotherapy Group, Faculty of Pharmacy, University of Benin, Benin City, 300001 Nigeria

\title{
Extraction optimization of Eucommia ulmoides Oliver and its effect on bone quality in OVX rats
}

\author{
ZhengNan Zhao ${ }^{1}$, XiangLong Yang ${ }^{1}$, Maoxun $\mathrm{Li}^{2}$, Fang $\mathrm{Yu}^{1}$, HaiDong Liang ${ }^{1 *}$ \\ ${ }^{1}$ Reparative and Reconstructive Surgery, The Second Hospital of Dalian Medical University, Dalian, Liaoning 116023, ${ }^{2}$ The \\ People's Hospital of Jimo, Qingdao, China \\ *For correspondence: Email: lianghddlf@sina.com; Tel: +86-0411-84671291
}

Sent for review: 6 September 2019

Revised accepted: 25 February 2020

\begin{abstract}
Purpose: To maximize the yield of extract from Eucommia ulmoides Oliver and its effect on bone quality.

Methods: Different extraction indices were optimized with response surface methodology (RSM) for maximization of extract yield from Eucommia ulmoides Oliver. Box-Behnken design (BBD) was used to identify the effects of temperature, time, and liquid to solid ratio on extract yield from Eucommia ulmoides Oliver. After 4-week acclimatization, thiry-two rats were randomly assigned to 4 groups $(n=8)$ : group 1 (sham) given vehicle only; group 2 (OVX rats given Eucommia ulmoides Oliver extract at a dose of $4 \mathrm{~g} / \mathrm{kg}$; group 3 (OVX + vehicle); group 4 (OVX + EUOE), i.e., OVX rats given Eucommia ulmoides Oliver extract $(4 \mathrm{~g} / \mathrm{kg})$. Sham rats had intact ovaries. After surgery, the rats received gentamicin intramuscularly for 3 successive days. Two months after surgery, blood and trabecular bones was taken for analysis.

Results: Temperature and liquid-to-solid ratio had marked impact on extract yield from Eucommia ulmoides Oliver, with the best conditions being temperature of $88^{\circ} \mathrm{C}$, time of $137 \mathrm{~min}$, and liquid to solid ratio 16:1. Using these optimized conditions, the maximum yield of extract obtained experimentally (2.53 $\%)$ was very close to the predicted value of $2.49 \%$. There was a good fit between the mathematical model evolved and the data on extract yield. The extract significantly $(p<0.01)$ increased the Ca and $P$ and $\mathrm{Cr}$ levels in OVX + EUOE group compared to those in OVX control. Moreover, the extract significantly $(p<0.01)$ increased macro-mechanical indices of trabecular bone in OVX+EUOE group, relative to those in OVX control.

Conclusion: The yield of Eucommia ulmoides Oliver extract has been successfully optimized using RSM. The extract exhibited strong effects on bone quality.
\end{abstract}

Keywords: Optimization, Eucommia ulmoides, Box-Behnken design, Response surface methodology, Bone loss, Gene

\begin{abstract}
This is an Open Access article that uses a fund-ing model which does not charge readers or their institutions for access and distributed under the terms of the Creative Commons Attribution License (http://creativecommons.org/licenses/by/4.0) and the Budapest Open Access Initiative (http://www.budapestopenaccessinitiative.org/read), which permit unrestricted use, distribution, and reproduction in any medium, provided the original work is properly credited.

Tropical Journal of Pharmaceutical Research is indexed by Science Citation Index (SciSearch), Scopus, International Pharmaceutical Abstract, Chemical Abstracts, Embase, Index Copernicus, EBSCO, African Index Medicus, JournalSeek, Journal Citation Reports/Science Edition, Directory of Open Access Journals (DOAJ), African Journal Online, Bioline International, Open-J-Gate and Pharmacy Abstracts
\end{abstract}

\section{INTRODUCTION}

Eucommia ulmoides Oliver (Eucommiaceae) is a medicinal herb in Traditional Chinese medicine
TCM) [1]. The medicinal parts of E. ulmoides are its stem bark and leaves. Several bioactive compounds with pharmacological effects have been isolated from $E$. 
ulmoides [1,2]. Pharmacological research has revealed that the leaves possess antihypertensive [3], anti-obesity [4] and antiinflammatory properties [2].

The effects of variable indices and their interactions are determined using RSM [5]. It is a very popular and reliable method for the optimization of operations involving plant products [6-8]. The technique minimizes the number of trials needed to ascertain the relationships among multiple factors, and it facilitates simultaneous investigations of numerous indices [9-11].

This study was carried out to develop effective response surface models to obtain optimal extract conditions from Eucommia ulmoides Oliver, based on temperature, time, and solid: liquid, for efficient extraction of Eucommia ulmoides. The effect of Eucommia ulmoides Oliver extract on bone quality in OVX rats was also investigated.

\section{EXPERIMENTAL}

\section{Preparation of extract from Eucommia ulmoides Oliver}

The Eucommia ulmoides Oliver was first refluxed with $90 \%$ ethanol for $5 \mathrm{~h}$. Then, the resultant residue was extracted with water at different temperatures for various tested times to obtain the aqueous extract. The supernatant fraction was concentrated and dried. Three major extraction parameters: temperature, time, and the liquid: solid ratio were considered in this study.

\section{Study design}

Experiments were conducted to optimize extract yield from $E$. ulmoides Oliver with RSM, using a 3- tier, 3-parameter BBD. The BBD permits investigation of factors to at least one at the center point (0) [12]. Variables such as temperature $(A)$, time $(B)$, and liquid: solid ratio (C) were used.

In all, 17 runs were used to measure extract yield, while maintaining the independent variables at levels $-1,0$, and +1 (Table 1). Optimum extraction conditions were chosen and validated on the basis of BBD results. Regression coefficients $(\beta)$ for assessment of the degree of influence of each factor on response were deduced from 3-D response surface plots. For individual responses, model F-value, absence of fit and $R^{2}$ were determined.

\section{Induction of osteoporosis in rats}

A total of thiry-two rats (mean bwt $=240 \pm 20 \mathrm{~g}$ ) were assigned to 4 groups (8 rats per group): vehicle-treated (sham, group 1); OVX rats treated with Eucommia ulmoides Oliver extract (4 $\mathrm{g} / \mathrm{kg}$, group 2); OVX + vehicle (group 3), and OVX rats given extract at a dose of $4 \mathrm{~g} / \mathrm{kg}$ b.w. Each aniaml was fasted for $6 \mathrm{~h}$ prior to excision of bilateral ovary under pentobarbitone anaesthesia $(50 \mathrm{mg} / \mathrm{kg})$. The ovaries of rats in the sham group were not removed. Post-surgery, gentamicin was administered intramuscularly to the rats for 3 successive days. Two months after surgery, blood and trabecular bones were taken for analysis.

\section{Tests on bone biomechanics}

Indices of biomechanics of L5 vertebrae were determined as described earlier [13].

\section{Statistical analysis}

Results are presented as mean $\pm S D$. The reliability of RSM calculations and equations were determined. Estimation of dissolution was done with 3 formulations chosen at random, using the experimentally-derived models.

\section{RESULTS}

\section{Optimized extraction temperature}

The influence of temperature on extraction yield of Eucommia ulmoides Oliver was studied (Figure 1). The results indicated a sharp rise in the extract yield with temperature up to $90{ }^{\circ} \mathrm{C}$, and a slow decrease subsequently (Figure 1). The highest extract yield $(2.42 \%)$ was obtained at $90{ }^{\circ} \mathrm{C}$. Therefore, extraction temperature of 90 ${ }^{\circ} \mathrm{C}$ was chosen for optimization of other parameters.

\section{Optimized extraction time}

The extraction yield from Eucommia ulmoides Oliver increased rapidly with time for about 140 min, with no increases thereafter (Figure 2). Maximum extract yield (2.39\%) was attained after $160 \mathrm{~min}$. Thus, $140 \mathrm{~min}$ was selected for optimizing other indices.

\section{Optimized liquid: solid ratio}

The optimum liquid: solid ratio was determined using a wide range of $11: 1$ to $-18: 1$. The optimum liquid-to-solid for maximum extract yield from Eucommia ulmoides Oliver extraction yield at solid-to-liquid ratio of 1:16 was $2.51 \%$ (Figure 3 ). 
Further increases in the liquid-to-solid ratio had no marked effect on extract level. Thus, the optimized solid-to-liquid ratio of 1:16 was used in subsequent experiments.

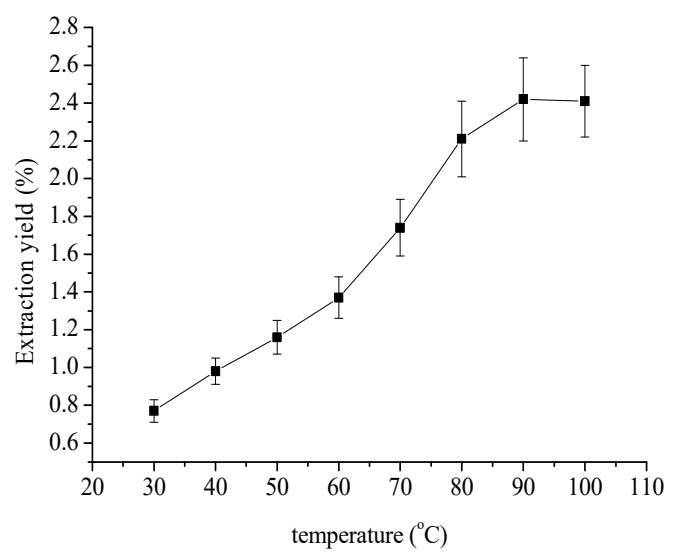

Figure 1: Influence of extraction temperature on extract level of Eucommia ulmoides Oliver

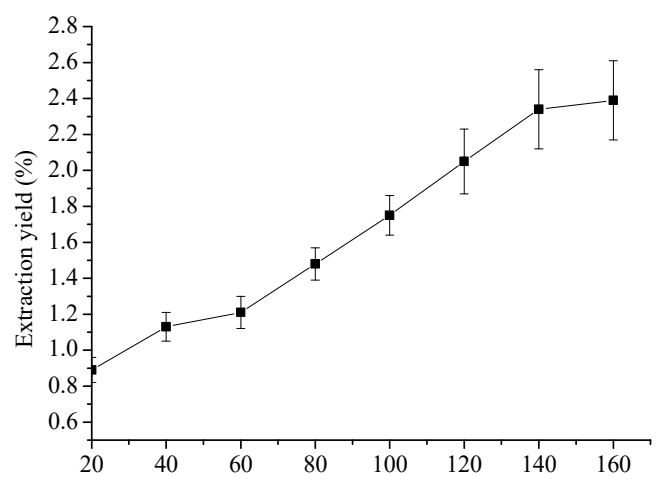

Figure 2: Influence of time on extract yield of Eucommia ulmoides Oliver

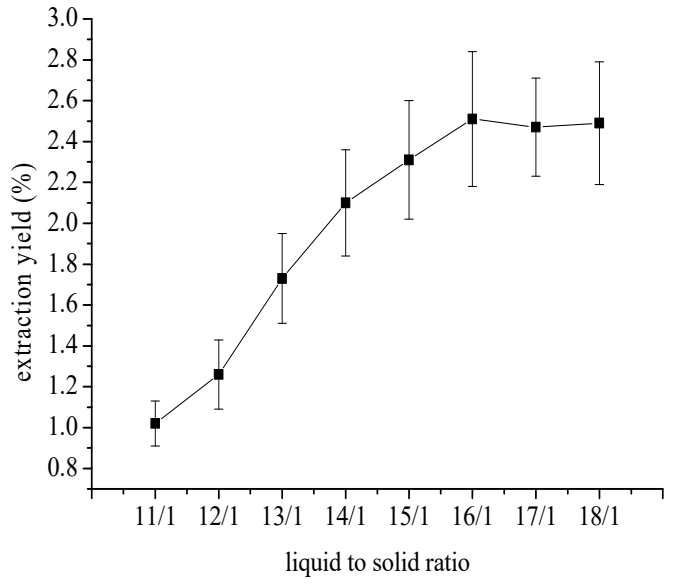

Figure 3: Influence of liquid: solid ratio on extract yield of Eucommia ulmoides Oliver

\section{RSM-optimized EUOE}

The experimental values of Eucommia ulmoides Oliver extraction yield varied from $1.93 \%$ to 2.47 $\%$ (Table 1).

The quadratic model was chosen as optimized model for EUOE extraction since the linear term was significant $(p<0.0001)$, as inferred from results of regression analysis in Table 3 .

Using optimized conditions i.e. temperature of 88 ${ }^{\circ} \mathrm{C}$, time of $137 \mathrm{~min}$ and solid: liquid ratio of 1:16 to test the model, the actual extract yield from Eucommia ulmoides Oliver was $2.53 \%(n=3)$, demonstrating that the experimental and predicted values were comparable $(p>0.05)$. Thus, the response model is adequate for use in optimizing extract yield.

Table 1: BBD and responses of variables

\begin{tabular}{|c|c|c|c|c|}
\hline Run & $\begin{array}{c}\text { A: Extraction } \\
\text { temperature }\left({ }^{\circ} \mathrm{C}\right)\end{array}$ & $\begin{array}{l}\text { B: Extraction } \\
\text { time (min) }\end{array}$ & $\begin{array}{c}\text { C: Liquid: solid } \\
\text { ratio }\end{array}$ & $\begin{array}{c}\text { R: Extract yield } \\
(\%)\end{array}$ \\
\hline 1 & -1.00 & -1.00 & 0.00 & 2.15 \\
\hline 2 & 1.00 & -1.00 & 0.00 & 2.39 \\
\hline 3 & -1.00 & 1.00 & 0.00 & 2.15 \\
\hline 4 & 1.00 & 1.00 & 0.00 & 2.38 \\
\hline 5 & -1.00 & 0.00 & -1.00 & 1.93 \\
\hline 6 & 1.00 & 0.00 & -1.00 & 2.28 \\
\hline 7 & -1.00 & 0.00 & 1.00 & 2.31 \\
\hline 8 & 1.00 & 0.00 & 1.00 & 2.47 \\
\hline 9 & 0.00 & -1.00 & -1.00 & 2.16 \\
\hline 10 & 0.00 & 1.00 & -1.00 & 2.17 \\
\hline 11 & 0.00 & -1.00 & 1.00 & 2.4 \\
\hline 12 & 0.00 & 1.00 & 1.00 & 2.39 \\
\hline 13 & 0.00 & 0.00 & 0.00 & 2.31 \\
\hline 14 & 0.00 & 0.00 & 0.00 & 2.3 \\
\hline 15 & 0.00 & 0.00 & 0.00 & 2.29 \\
\hline 16 & 0.00 & 0.00 & 0.00 & 2.3 \\
\hline 17 & 0.00 & 0.00 & 0.00 & 2.29 \\
\hline
\end{tabular}

Table 2: Analysis of variances (ANOVA) for RSM-BBD model 


\begin{tabular}{|c|c|c|c|c|c|c|}
\hline Source & $\begin{array}{l}\text { Sum of } \\
\text { squares }\end{array}$ & df & $\begin{array}{c}\text { Mean } \\
\text { square }\end{array}$ & $\begin{array}{c}F \\
\text { Value }\end{array}$ & $\begin{array}{l}P \text {-value } \\
\text { Prob > F }\end{array}$ & \\
\hline Model & 0.27 & 9 & 0.03 & 103.89 & $<0.0001$ & Significant \\
\hline $\mathrm{A}$ (temp., ${ }^{\circ} \mathrm{C}$ & 0.12 & 1 & 0.12 & 419.13 & $<0.0001$ & \\
\hline$B(\min )$ & $1.25 \mathrm{E}-05$ & 1 & 1.25E-05 & 0.044 & 0.8405 & \\
\hline C (liquid:solid ratio) & 0.13 & 1 & 0.13 & 462.99 & $<0.0001$ & \\
\hline$A B$ & 2.50E-05 & 1 & 2.50E-05 & 0.087 & 0.7762 & \\
\hline$A C$ & 9.03E-03 & 1 & 9.03E-03 & 31.51 & 0.0008 & \\
\hline $\mathrm{BC}$ & 1.00E-04 & 1 & 1.00E-04 & 0.35 & 0.5732 & \\
\hline$A^{\wedge} 2$ & 4.18E-03 & 1 & 4.18E-03 & 14.59 & 0.0065 & \\
\hline$B^{\wedge} 2$ & 4.21E-06 & 1 & 4.21E-06 & 0.015 & 0.9069 & \\
\hline$C^{\wedge} 2$ & $1.52 \mathrm{E}-03$ & 1 & $1.52 \mathrm{E}-03$ & 5.31 & 0.0547 & \\
\hline Residual & 2.01E-03 & 7 & $2.86 \mathrm{E}-04$ & & & \\
\hline Lack of Fit & 1.73E-03 & 3 & 5.75E-04 & 8.21 & 0.0348 & Significant \\
\hline Pure Error & 2.80E-04 & 4 & 7.00E-05 & & & \\
\hline Cor Total & 2.70E-01 & 16 & \multirow{2}{*}{\multicolumn{2}{|c|}{ R-Squared }} & & \\
\hline SD & 0.017 & & & & 0.9926 & \\
\hline Mean & 2.27 & & \multicolumn{2}{|c|}{ Adj R-Squared } & 0.9830 & \\
\hline C.V. \% & 0.74 & & \multicolumn{2}{|c|}{ Pred R-Squared } & 0.8961 & \\
\hline PRESS & 0.028 & & \multicolumn{2}{|c|}{ Adeq Precision } & 38.713 & \\
\hline
\end{tabular}

\section{Effect of EUOE on $\mathrm{Ca}$ and $\mathrm{P}$ and $\mathrm{Cr}$ levels in OVX rats}

The experimental analyses revealed that the $\mathrm{Ca}$ and $\mathrm{P}$ and $\mathrm{Cr}$ levels in sham were markedly higher than those in OVX control (Figure 5 and Figure 6). However, there were greater decreases in the $\mathrm{Ca}$ and $\mathrm{P}$ and $\mathrm{Cr}$ levels in OVX + EUOE rats than in OVX control (Figure 5 and Figure 6). There were no marked differences in any of the parameters between the sham, and sham + EUOE groups.

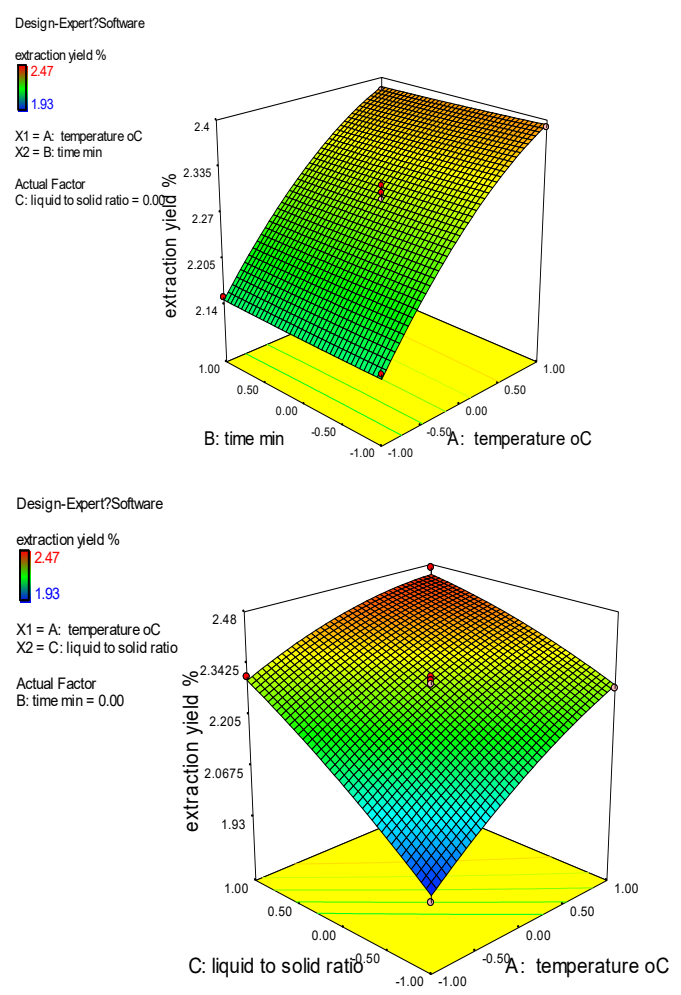

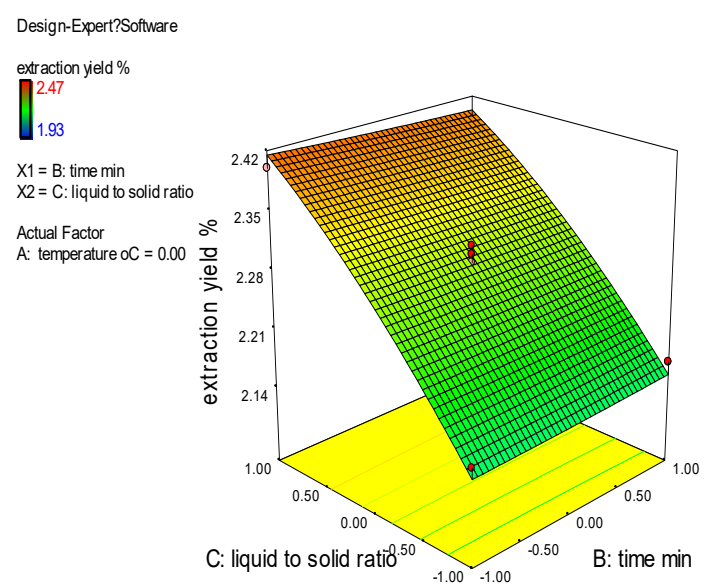

Figure 4: Response surface showing the interaction between three parameters. $(A$ and $B)$ temperature $\left({ }^{\circ} C\right)$ and time ( $\min )$; ( $\mathrm{A}$ and $\mathrm{C}$ ) temperature $\left({ }^{\circ} \mathrm{C}\right)$ and liquidto-solid ratio; ( $B$ and $C$ ) time $(\mathrm{min})$ and liquid: solid ratio

\section{Impact of EUOE on biomechanical parameters in OVX rats}

Table 3 indicates that macro-mechanical indices were markedly higher in sham rats than in OVX rats. Ultimate load was markedly greater in OVX + EUOE group, relative to OVX groups. The stiffness was significantly greater in the OVX + EUOE group when compared to the OVX groups. The energy to failure was significantly greater in OVX + EUOE group than in OVX groups. The other indices were comparable among the sham, and sham + EUOE groups. 
Table 3: Effect of EUOE on ultimate load, stiffness and energy to failure in OVX rats

\begin{tabular}{|c|c|c|c|}
\hline Group & Ultimate load (N) & Stiffness (N/mm) & Energy to failure (mJ) \\
\hline Sham & $389.71 \pm 33.95^{* *}$ & $29.75 \pm 2.22$ ** & $215.77 \pm 18.45^{* *}$ \\
\hline OVX & $278.43 \pm 23.62$ & $19.41 \pm 1.64$ & $164.93 \pm 12.58$ \\
\hline Sham + EUOE $(4 \mathrm{~g} / \mathrm{kg})$ & $390.53 \pm 30.14$ & $31.53 \pm 26.38$ & $217.95 \pm 20.99$ \\
\hline OVX + EUOE $(4 \mathrm{~g} / \mathrm{kg})$ & $376.21 \pm 28.59$ \#\# & $25.52 \pm 20.51 \#$ & $201.39 \pm 18.47$ \#\# \\
\hline
\end{tabular}

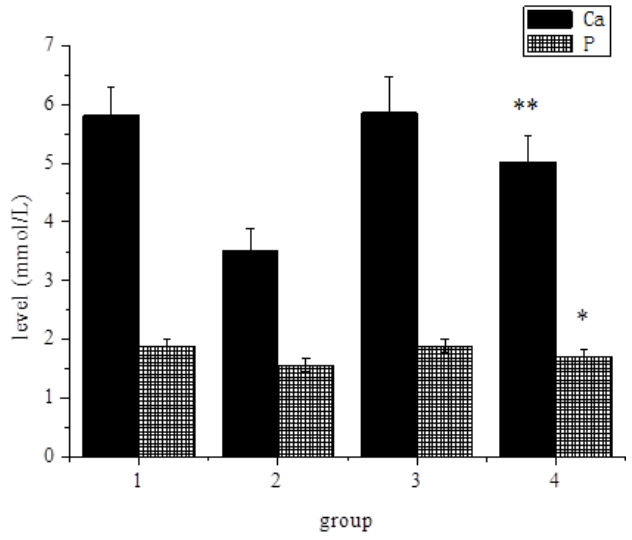

Figure 5: Effect of EUOE on blood $\mathrm{Ca}$ and $\mathrm{P}$ levels in OVX rats

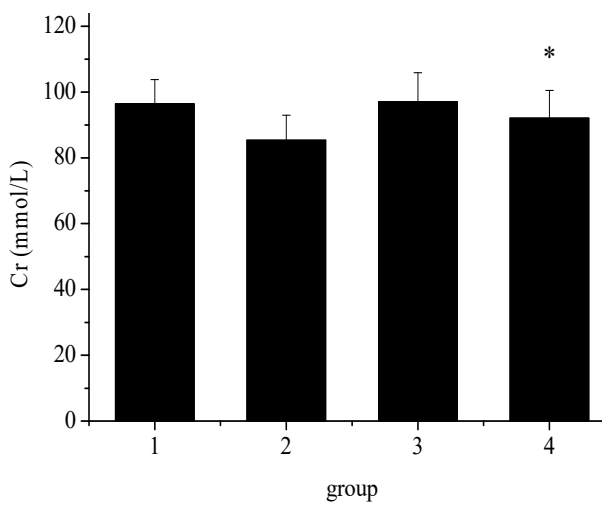

Figure 6: Effect of EUOE on blood $\mathrm{Cr}$ levels in OVX rats

\section{DISCUSSION}

In this optimization, yields in range of parameters are shown in Table 1. Some specimens were prepared and tested based on these optimized values, and their mean values were obtained. Using linear regression and statistical analysis $[14,15]$, the results demonstrated that all the input parameters had significant impacts on yield of extract from EUOE. Temperature and solid: liquid ratio had the most effect on extract yield. The interaction plot indicated significant interaction between the temperature and liquid: solid ratio with respect to extract yield which is also evident in the output mathematical model of yield response.
The response points are assessed based on 3D response surface and 2D contour plots [16]. There were marked interactions between temperature and liquid: solid ratio. These two factors had the highest influence on extract levels.

In Japan, Eucommia ulmoides Oliver is called Tuchong, while Chinese call it Du-zhong Chinese) [17]. It is a deciduous tree which belongs to the family of Eucommiaceae [18]. The present study showed that EUOE treatment improves $\mathrm{Ca}$ and $\mathrm{P}$ and $\mathrm{Cr}$ levels and trabecular bone biomechanical properties in OVX rats

\section{CONCLUSION}

The extraction conditions for Eucommia ulmoides Oliver have been successfully optimized using RSM. The optimized conditions obtained are temperature of $88{ }^{\circ} \mathrm{C}$, time of $137 \mathrm{~min}$ and solidto-solid ratio of $1: 16$. The results suggest that EUOE has potential for application in the suppression of bone degeneration in humans.

\section{DECLARATIONS}

\section{Acknowledgement}

This work was supported by a grant from the Liaoning Provincial Science and Technology Department(No.2019-MS-100)

\section{Conflict of interest}

No conflict of interest is associated with this work.

\section{Contribution of authors}

We declare that this work was done by the authors named in this article and all liabilities pertaining to claims relating to the content of this article will be borne by the authors.

\section{Open Access}

This is an Open Access article that uses a funding model which does not charge readers or their institutions for access and distributed under the terms of the Creative Commons Attribution 
License (http://creativecommons.org/licenses/by/ 4.0) and the Budapest Open Access Initiative (http://www.budapestopenaccessinitiative.org/rea d), which permit unrestricted use, distribution, and reproduction in any medium, provided the original work is properly credited.

\section{REFERENCES}

1. He XR, Wang JH, Li MX, Hao DJ, Yang Y, Zhang CL, He $R$, Tao R. Eucommia ulmoides Oliv.: ethnopharmacology, phytochemistry and pharmacology of an important traditional Chinese medicine. J Ethnopharmacol 2014; 151: 78-92

2. Bai MM, Shi W, Tian JM, Lei M, Kim JH, Sun YN, Kim $Y H$, Gao JM. Soluble epoxide hydrolase inhibitory and anti-inflammatory components from the leaves of Eucommia ulmoides Oliver (Duzhong). J Agric Food Chem 2015; 63: 2198-2205

3. Yamaguchi $Y$, Kawamura $N$, Tsuboi $T$, Yamaguchi $Y$, Hirata T, Ueda T, Tagawa C, Nakazawa Y, Onizuka S, Tagashira E. Effect of the Eucommia ulmoides Leaf Extract on Blood Pressure. International Symposium on Eucommia Ulmoides, 2007; 1 (1) :55-62

4. Hirata $T$, Kobayashi $T$, Wada A, Ueda T, Fujikawa $T$, Miyashita $H$, Ikeda T, Tsukamoto S, Nohara T. Antiobesity compounds in green leaves of Eucommia ulmoides. Bioorg Med Chem Lett 2011; 21: 1786-1791

5. Bas D, Boyacı IH. Modeling and optimization I: usability of response surface methodology. J Food Eng 2007; 78: 836-845

6. Abreu M, Beirao-da-Costa S, Gonçalves EM, Beirão-daCosta ML, Moldão-Martins M. Use of mild heat pretreatments for quality retention of fresh-cut 'Rocha pear'. Postharvest Biol Technol., 2003; 30: 153-160

7. Ölmez $H$, Akbas MY. Optimization of ozone treatment of fresh-cut green leaf lettuce. J Food Eng 2009; 90: 487494

8. Ting $X J$, He GQ, Chen $Q H$, Zhang $X Y$, Ali MA. Medium optimization for the production of thermal stable glucanase by bacillus subtilis ZJF-1A5 using response surface methodology. Bioresour Technol 2004; 93: 175181

9. Dinarvand $M$, Rezaee $M$, Masomian $M$, Jazayeri $S D$, Zareian M, Abbasi S, Ariff AB. Effect of $C / N$ ratio and media optimization through response surface methodology on simultaneous productions of intraextracellular inulinase and invertase from Aspergillus niger ATCC 20611. BioMed Res Int 2013; 2013: 1-13

10. Darija V, Zelimir K, Andrelina M. Optimisation of inulinase production by Kluyveromyces bulgaricus. Food Technol Biotechnol 2002; 40: 67-73

11. Madhavi RS, Lele SS. Increased production of extracellular laccase by the white rot fungus coriolusversicolor MTCC138. World J Microbiol Biotechnol 2006, 22: 921-926

12. Rahman N, Sameen S, Kashif M. Application of BoxBehnken design and desirability function in the optimization of spectrophotometric method for the quantification of WADA banned drug: Acetazolamide. $\mathrm{J}$ Molec Liquids, 2019; 274: 270-277

13. Zhang G, Qin L, Hung WY, Shi $Y Y$, Leung PC, Yeung $H Y$, Leung KS. Flavonoids derived from herbal Epimedium brevicornum Maxim prevent OVX-induced osteoporosis in rats independent of its enhancement in intestinal calcium absorption. Bone, 38 (2006), pp. 818825

14. Surendra TV, Roopan SM, Arasu MV, Al-Dhabi NA, Rayalu GM. RSM optimized Moringa oleifera peel extract for green synthesis of $M$. oleifera capped palladium nanoparticles with antibacterial and hemolytic property. J Photochem Photobiol B 2016; 162: 550-557

15. Hatami M. Nanoparticles migration around the heated cylinder during the RSM optimization of a wavy-wall enclosure. Adv Powder Technol2017; 28(3): 890-899

16. Belwal T, Dhyani $P$, Bhatt ID, Rawal RS, Pande V. Optimization extraction conditions for improving phenolic content and antioxidant activity in Berberis asiatica fruits using response surface methodology (RSM). Food Chem 2016; 207: 115-124

17. Kwon SH, Ma SX, Hong SI, Kim SY, Lee SY, Jang CG. Eucommia ulmoides Oliv. bark. attenuates 6hydroxydopamine-induced neuronal cell death through inhibition of oxidative stress in SH-SY5Y cells. J. Ethnopharmacol 2014; 152: 173-182

18. Hao S, Xiao $Y$, Lin $Y$, Mo Z, Chen $Y$, Peng X, Xiang C, Li $Y$, Li W. Chlorogenic acid-enriched extract from Eucommia ulmoides leaves inhibits hepatic lipid accumulation through regulation of cholesterol metabolism in HepG2 cells. Pharm. Biol., 2016; 54: 251259 